\title{
Using a Narrative Tool to Help Quebec English-Speaking Students Produce Personal Histories of Belonging
}

\author{
Paul Zanazanian and Nathalie Popa
}

\begin{abstract}
This article introduces Jörn Rüsen's concept of narrative competence as a useful pedagogical framework for operationalizing a remedial narrative tool designed to help make room for Quebec's English-speaking minority in the teaching of school history. Developed through empirical research and representing a schema-like narrative structure, the Narrative Template Tool's aim is to assist students to produce and validate personal (his)stories of belonging through conducting original historical research. To counter the dangers of indoctrination, the tool moreover employs a feature of the orientation component of narrative competence-use-of-history-as a means of helping students account for their emerging perspectives.
\end{abstract}

\section{Background}

This article introduces Jörn Rüsen's (2005) concept of narrative competence and employs it to operationalize a Narrative Template Tool designed to help English-speaking youth in Quebec produce and validate (his)stories of belonging through the teaching of school history (Zanazanian, 2017a; 2017b). The way narrative structures historical consciousness offers a unique opportunity for giving a voice to English-speaking youth as members of a misunderstood historic minority and, by extension, for strengthening their community's weakening vitality. If used carefully, the narrative tool can make room for students' lived experiences within a larger understanding of their community's history. In offering a narrative framework whose inner stories are empty and waiting to be filled with content, students are given the necessary resources, skills, and autonomy to freely develop personal histories in well-informed and well-reasoned ways. Comprising a schema-like narrative structure, the tool has been developed empirically and serves as a cultural script or "receptacle" for clasping together the fragmented bits of information of English-speaking Quebec's past that students may possess and further gain through inquiry-based research projects. To counter the dangers of reifying the past and indoctrination, the tool's operationalization moreover enables students to account for the perspectives they put forth when transforming these fragmented histories into meaningful and usable narratives of the past (Zanazanian, 2017a; 2017b).

In what follows, we first set the stage justifying narrative's role and relevance for helping make space for English-speaking Quebec in the teaching of history, and, by extension, for other historic minority communities, whose realities and experiences may also be excluded from school history programs. We then define the notion of narrative competence, and explain each of its three sub-competencies: experiencing the past in the present; interpreting evidence of the past in the form of history, and using 
historical knowledge to orient oneself in life (Rüsen, 2005). Next, we describe the tool, what it is and how it functions, and detail how it can be operationalized via Rüsen's (2005) narrative competence lens. We conclude by elaborating on the concept of use-of-history, a feature of the third sub-competency of orientation, for getting students to account for their positionality when producing their histories.

\section{Why Narrative for Making Room for English-Speaking Quebec in School History}

Concerned with the social justice implications of historical knowledge and its impact on human agency, the Narrative Template Tool's aim is to populate students' cultural toolkits for giving meaning to their social reality as English-speakers and to hence inform the workings of their historical consciousness. The tool seeks to create space for students' lived community experiences within a historical framework from their own perspectives, where they account for what they produce, and not something that is imposed on them. Such an approach provides an important avenue for accessing and assisting students' sense-making processes for remedial purposes of fostering social change. It is known that the content and form of the narratives humans use for making sense of reality, including understandings of the historical past, affect how they perceive, explain, and give meaning to events and life experiences. These narratives further influence the manner in which they negotiate coherency, connectedness, situatedness, belonging, and intentionality for living their lives (Bruner, 1990; Polkinghorne, 1988; Straub, 2005). This is especially the case when acting as members of self-identifying collectives through time. It is through offering English-speaking Quebec the necessary mechanisms for organizing their life experiences in meaningful ways, to then independently channel their ideas to successfully unify and mobilize as a group, that this use of narrative as a historical resource tool can be attained.

Despite its exploratory nature, the tool's structure and logic are nonetheless grounded in strong theoretical and empirical scholarship in the areas of history and memory studies, with cross-disciplinary roots in cultural psychology, sociology, historiography, and the teaching and learning of history (Polkinghorne, 1988; Bruner, 1990; Halbwachs, 1992; Assmann \& Czaplikca, 1995; Wertsch, 1998; Rüsen, 2005). Introducing narrative as a pedagogical device can provide cultural scripts that enable students to develop coherency and meaning as well as an ability to recount and verbalize life experiences. Based on our cross-disciplinary approach, narrative's strength particularly lies in its ability to structure and give order to social reality for purposes of knowing and acting in time. It helps give meaning to experiences of change and contingency that would otherwise overwhelm users and confuse and disorient them. Such an affordance is, however, not without its limits and dangers. Lacking awareness of this "simplification" process-and its centrality in how humans employ narrative for purposes of organizing knowledge—can be detrimental to fostering openness to differences in and beyond the classroom. If not used properly, narrative, as a mode of thought, can hamper intercultural dialogue and instead reinforce boundaries between individuals and groups. As a countermeasure, the key would be to activate curiosity to limit such negative potentials and to teach students about the practical, political, and cultural workings of narratives, their relationship to historical consciousness, 
and their particular relevance for navigating the world. This requires an open use of the narrative tool to ensure that students are able to take critical distance from their knowledge claims.

The tension between affordance and limits/dangers comprises a sort of paradox that the narrative tool and its operationalization try to address, especially for making room for minority experiences in the teaching of history. The tension lies between promoting the need for presenting the past as complexwhich is what many history teachers strive to do to prepare critical and autonomous thinkers-and fostering a common narrative identity to the ends of helping a weakening community know, see, and recognize itself as a historic entity for purposes of group vitality. In line with the Quebec history program's promotion of the historical method/historical thinking, the paradox arises when looking at the limits of disrupting master narratives in classroom settings. It is generally understood that room can be made for historic minority communities when teaching history by bringing in a disciplinary-based understanding of how history works. The idea is that master narratives are ultimately constructed, and can be disrupted (in a rigorous manner) to show that they mask diverse realities, perspectives, and nuances. By transmitting elements of the historic method/historical thinking, students are to exercise and develop critical thinking skills and to eventually come up with well-informed and well-reasoned conclusions on the past based on evidence. Although such an approach highlights the complexity of master narratives, the question remains whether it can really make room for historic minorities, who may feel marginalized. Historical thinking may open up pre-given understandings of the past to bring in minority perspectives, but a sole reliance on it when reliable content knowledge on such groups (where they are the protagonists of their story) is greatly missing, as is usually the case, is questionable.

Notwithstanding teachers' own sense of purpose or motivation, the challenge then is that of making room for English-speaking Quebec when adequate content knowledge on their various histories is absent, while also facing pressure to promote a form of "national" Quebec identity. Core researchers in the field of history education have suggested that if teachers, when problematizing and presenting official state or master narratives as complex, do not bring in some form of narrative framework that can help (minority) students clasp such a deconstructed complexity, the dominant group's power, norms, and narrative control of history will inadvertently be reinforced (Epstein, 2008; Barton, 2012; Létourneau, 2015). In such instances, making space for English-speaking Quebec would only be superficial. The assumption in this article is that historic minority youth (who feel/are marginalized would) need readily available narrative scripts or templates to help grasp together what is broken and to help their developed perspectives fit into a larger picture-one that works and one that is not imposed.

The usable narrative framework, conceived as a form of a narrative template, as we propose here, is important for making room for minority communities who feel excluded from the school history curriculum. What we suggest can nonetheless be likened to the Historical Narrative Inquiry Model developed by Colby (2008). This instructional model aims to teach procedural knowledge, enhance interpretative skills, cultivate historical perspectives based upon evidentiary history, and encourage student authorship of historical narratives. The model includes a cyclical six-stage process: contextual beginnings, in-depth questioning, secondary source analysis, primary document analysis, student authorship, and philosophical/argumentative reflection. The model supports small- and large-group 
activities, including oral presentations, discussions about primary documents, and considerations relative to the creation of written history. The purpose of Colby's (2008) model is to encourage analytical thinking and facilitate students' historical understandings by developing more empathetic perceptions of the people of the past. Our pedagogical tool is based on considerations similar to those underlying Colby's instructional model, but focuses more specifically on promoting history teaching that supports students in developing narratives of belonging.

\section{The Workings of Narrative Competence}

Over the past few years, researchers in the field of history education have increasingly given attention to the implications of developing young people's narrative competence for life orientation purposes. They have developed models of historical sense-making based on the notion's component parts (Körber \& Meyer-Hamme, 2015; Eliasson, Alven, Yngveus, \& Rosenlund, 2015; Waldis, Hodel, Thünemann, Zülsdorf-Kersting, \& Ziegler, 2015). Their work is notably influenced by Rüsen's (2005) theoretical account of the concept, defined as the ability to narrate a story by means of which "practical life is given an orientational locus, or a place, in time" (p. 36). In this process, learners discover who they are as individual users of narrative and, moreover, grasp how historical consciousness influences their decision-making for navigating the world. Rüsen (2005) outlines three fundamental elements of any given narrative-content, form, and function-and three corresponding dimensions that underlie the guiding function of narrative competence-experience, interpretation, orientation. Building on this, educational models of historical sense-making have particularly integrated research findings over the past several years on students' historical thinking (Köster, Thünemann, \& Zülsdorf-Kersting, 2014; Stearns, Seixas, \& Wineburg, 2000; Wineburg, 2001), as well as literature on historical consciousness (Ahonen, 2005; Angvik \& von Borries, 1997; Lee, 2004; Seixas, 2004, Wilschut, 2012) for expanding the concept.

Drawing on this scholarship, narrative competence in this paper involves three sub-competences: having experience; actuating interpretation; and enabling orientation.

Experience is achieved through developing students' sensitivity to the presence of the past around them. Key to this is recognizing the past's temporal quality and how its realities are different from present-day ones. Experience involves expanding students' awareness that the past permeates their lives in ordinary and unexpected ways, and that the distances between past and present are not necessarily fixed by chronology, but can be subjective and malleable. This requires guiding students to come into contact with and relate to many prior events and to see the past in and of itself for its intricate details and complexities. Using material, visual, or textual objects as prompts can help with this, which can be found in family history, community heritage, architecture, museums, popular culture, or public sites of memory and practices of remembrance. These encounters are mostly experiential, and encourage students to see, touch, and feel traces of the past. Learning history in this sense appeals to students' curiosity and imagination, their sense of discovery, wonder, and emotional engagement with historical content, which they will use for providing their own perspectives of the past (van Boxtel, Grever, \& Klein, 2016).

368 | LEARNing Landscapes | Spring 2018, Vol. 11 No. 2 
Using a Narrative Tool to Help Quebec English-Speaking Students Produce Personal Histories of Belonging

Interpretation refers to the ability to find meaning in the past and to organize such acquired historical knowledge into a comprehensive whole or "picture" of the past that can later be employed for reflection and argumentation. Interpretation specifically involves portraying or making newly gained experience look plausible in the first, above-mentioned, sub-competence through espousing a rigorous methodology for transforming and narrativizing how things could have happened. Learning history in this sense involves delving into the methods and habits of historians' minds, and the creative procedures they go through to construct meaningful histories. In this process, students become familiar with historians' tools of inquiry as well as with the role of historical empathy and the structure of historical narratives (Barton \& Levstik, 2004). To do this involves: posing historical questions; examining historical sources as evidence to formulate historical arguments and critically analyze historical claims; recognizing and applying such historical thinking dimensions as historical perspectives (including the avoidance of presentism), historical significance, and change and continuity (see below); and examining key features of narrative, including, cast, setting, sequence, emplotment, and underlying related schematic templates.

Orientation holds as its objective the ability to use the "pictures" of the past developed through interpretation as a means of reflecting on one's positionality in present times. It relates to understanding the different uses of individuals' interpretations of the past for navigating their everyday lives, which intimately involves getting students to reflect on their adopted historical point of view (VanSledright, 1998). Students are thus given opportunities to do something with history, namely to relate gained historical knowledge and understanding to their own life and society, and to further employ this information to inform personal standpoints on present situations and future possibilities (Nordgren, 2016). Key, however, is for learners to grasp the historicity of both themselves and their world, and to employ this insight for authoring their agency. As we shall see below, learning history in this way can encourage students to see the reasons for using history for orientational purposes: to explain the surrounding world, to form identities, and to exert influence (Nordgren, 2016).

\section{Description of the Narrative Template Tool for English-Speaking Quebec}

School history programs in many western countries make it their chief goal to transmit usable master narratives that configure coherent historical understandings of national pasts. The content of these usually reflects the main identity markers of a given state's dominant group and can be influential in how young people employ history when negotiating their sense of national identity and agency (Barton \& Levstik, 2004; Carretero, Asensio, \& Moneo, 2012; Carretero, Berger, \& Grever, 2017; Clark, 2011; Epstein \& Peck, 2017; Zanazanian \& Moisan, 2012). In this process, as part of the "nation-building" format, historic minority communities can nonetheless be easily left out. Sentiments of alienation can result and can become all the more amplified when reduced group depictions contradict a minority community's self-awareness and relegate particular simplified roles to its members.

Quebec provides a similar context regarding the politics of narrative control and inclusion in the teaching of school history, especially regarding its historic English-speaking minority and Indigenous populations. One important challenge when seeking to make curricular space for these excluded groups from the 
program is to help them find a voice- a voice that permits sharing information about their presence and contributions to the state as protagonists of their story and one that enables their youth to know and act as members of larger society in their own right as individuals from legitimate historic communities (QCGN, 2009; Canadian Heritage, 2009; Canadian Standing Senate Committee on Official Languages, 2011). Caution, however, is needed when proceeding in this manner. This is important given Quebec's context of history teaching and contested identities between its French- and English-speaking communities, including the ongoing limited treatment of the province's Indigenous communities as well as the "silencing" of the core historical experiences of various historic groups, such as the Irish and Blacks. As such, the Narrative Template Tool addresses the English-speaking minority's absence from Quebec's official state history program, seeking to encourage sentiments of group identity, belonging, and valued inclusion among its youth, while also respecting the past experiences and memories of Quebec's Francophone, Indigenous, and other minority groups (Zanazanian, 2017a; 2017b). Given the Francophone majority's own concerns of linguistic and cultural fragility in North America and the general attachment to their historical memory for forming the program's main storyline, the intent is to further make room for English-speakers' diverse presence and contributions by complementing Quebec's official history program, and not by replacing it through the use of the narrative tool (Zanazanian, 2017a; 2017b).

Inspired by the ideas of cultural psychologist James V. Wertsch $(1998,2004)$ and by those of Quebec historian Jocelyn Létourneau $(2006 ; 2014)$, the Narrative Template Tool comprises a core skeletal storyline or narrative script, specifically drafted for producing and promoting much-needed coherent identity frameworks among English-speakers' increasing cultural, regional, and generational differences. Based on Wertsch's $(1998 ; 2004)$ notion of schematic narrative templates, the tool's template-like structure can be defined as: a culturally available skeleton plot of generalizable storylines that provides a core narrative framework for underlying many instances of a broad range of community narratives that group members may recite and relate to. In offering a basic, workable plotline that resonates with group members' experiences (and, by extension, those of Quebec's Francophone majority), English-speakers would be better prepared to give meaning to the past for guiding their sense of identity and civic engagement in the province.

In following this logic, the tool is designed to work as an interactive framework. The intent is for teachers to engage their students in learning the history of English-speaking Quebec, with the main objective of having students use this narrative structure to produce their own stories of belonging through investigative historical research. To these ends, the narrative tool's cultural script acts as a "receptacle" for clasping together and framing students' researched perspectives within a larger understanding of the history of the English-speaking community, thereby aiming to offer them coherency, meaning, and an ability to narrativize and verbalize their (historical) experiences.

Designed by Paul Zanazanian (2017a; 2017b), the Narrative Template Tool's script was created based on empirical findings from a research project that examined the workings of community leaders' historical consciousness and its impact on shaping their strategies for helping vitalize English-speaking Quebec. As part of this study, participants' historical memories were looked at, the main markers of 
which were produced through analyzing the data in a rigorous manner following a narrative approach and espousing at least two methods of analysis for triangulation purposes. Community leaders are important trendsetters holding the strong potential of informing group members' toolkits for knowing and acting as English-speakers. An official report by the Canadian Standing Senate Committee on Official Languages (2011), outlining a call for both English and French speakers in the province to specifically work together to address their respective vitality issues, moreover provided the legitimated direction needed for framing the tool.

As part of this study, participants answered an open-ended historical writing task, where they narrated the history of English-speaking Quebec from the very beginnings until current times. This method was adopted from Létourneau's (2004) own research on Francophones Quebecers' historical memory and served to develop the template's schematic structure. Content analysis was used to analyze the data and a narrative data reduction technique served to help triangulate the findings. The analysis permitted attaining input regarding the main dates, events, actors, and periods as well as central turning points and structural narrative patterns that emerged in participants' histories. The main turning points that surfaced were placed in chronological order and the emerging narrative threads that were the most conducive to fostering a positive sense of Self and living together with Francophones were specifically selected. The Diversification through immigration thread as a thematic undercurrent of participants' narratives and the smaller theme of Working together with Francophones to build a common civic project were favored over Group duality representing a history of two homogeneous entities in constant competition. The English-speaking Quebec template was then segmented into the following periods chronologically, viewing the two adopted themes as threads interlacing across them:

(1) Beginnings (From New France to the Change of Empire, prior to 1760)-a period in Englishspeakers' history that represents initial contact with Francophones and Indigenous populations in Quebec.

(2) Presence and Contributions (From the Change of Empire to the Quiet Revolution, between 1760 and 1960) - a period of the past that refers to English-speakers' arrival, diversification, eventual development, and ongoing practice of responsible government.

(3) Change and Challenges (From the Quiet Revolution to Current Times, between 1960 and the end of the 1990s) - a period of social realignment, resulting in the protection of French as well as in the exodus of many English-speakers from Quebec, eventually placing those who remained at a crossroads to figure out how to deal with their changing realities.

(4) Adaptation (Current Times) - today's moment and potential of embracing new realities, and collaborating with Francophones (and other communities) to make things work.

(5) Promise (The Future) — important moments that are to come and serve as opportunities for forging a common civic project based on mutual respect and dialogue (including the need to redress grievances of Quebec's Indigenous populations).

In employing this schema-like framework, teachers can guide students to develop their own histories by helping them to think and weave their stories like historians do. Conducting original historical research and using the narrative tool to produce a resulting history would allow students to develop their own opinions about the past, rather than bathing in those presented to them by authority figures who may have their own personal agendas. By engaging in the process of producing their personal narratives, 
not only would students learn about history and how history is done, but they would also learn about how their society uses historical narratives, what the different benefits and drawbacks of such uses are, and how these can influence their historical positionality as group members and future citizens. Students would furthermore be made aware of the importance of being accountable for the choices they make in producing their narratives of belonging. This would allow them to validate their stories of belonging and to also better understand and be more open to the history program they are being taught.

\section{How the Tool Functions via Narrative Competence}

In terms of employing the Narrative Template Tool with narrative competence, the constructivist and dialogic pedagogical approaches are most appropriate (e.g., Phillips, 2000; Renshaw, 2004). Constructivism is based on the assumption that learners need to build their own understanding of new ideas by drawing on previous knowledge and new information, and this process of constructing knowledge, rather than acquiring it, is contextualized. The constructivist teacher sets up problems and guides student inquiry in a way that encourages learners to actively construct meanings by getting their feet wet, rather than passively receiving ready-made meanings. The role of the teacher, thus, is interactive - to facilitate and support students in using prior knowledge to build new knowledge. Constructivist teaching and learning strategies include employing case studies, role-playing, and graphic organizers like concept maps, because these offer opportunities to demonstrate or perform what students know, thus making understanding more explicit.

Dialogic teaching uses dialogue, or talk, to stimulate and extend students' understandings and learning. It is based on the assumption that knowledge means different things to different people, and in different contexts, and the dialogue between these different perspectives leads to new knowledge and understandings. Learning through dialogue involves constructing meanings from the inside, that is, within a community of learners, rather than having meanings imposed from the outside. From this perspective, what drives much of classroom instruction is not direct instruction, but rather skillful questioning. That being said, the teacher's questions should not probe for set answers, nor should they close down exploration. Instead, they should expose tensions and contradictions in students' thinking, and strive to elicit new thinking. In addition to thoughtful questioning, a dialogic perspective promotes careful listening, as well as opportunities for respectful and open-ended discursive interactions, and welcomes student input regarding content and assignments. Dialogic teaching strategies include discussions, collaborative learning, and regular teacher feedback.

Such an initial mindset to teaching and learning is helpful for employing the narrative tool presented in this article. Rüsen's (2005) narrative competence framework provides further insight into how to concretely put it into practice and into how to draw learning experiences from it for students. In basing the tool's use on the experience, interpretation, and orientation format described above, teachers can sequence their teaching in the following manner. 
The first level of narrative competence as outlined in this paper has students looking for connections between past and present, and seeing traces of the past as living history. One way to pique students' interest and get them personally involved in experiencing the temporal quality of histories in their environment and culture is to take students on a fieldtrip to a museum, or to organize activities that incorporate objects and photographs into lessons. Either way, students could be asked to pick an object or photograph that in their view is related to one of the first three periods of English-speaking Quebec's history as outlined by the narrative tool (Beginnings; Presence and Contributions; and Change and Challenges), then to reflect upon their personal relation to that object, and explain to others how that object or photograph speaks to the last two periods of English-speaking Quebec's history (Adaptation; and Promise). Teachers could raise questions and encourage students to develop cognitive and emotive understandings about these objects or photographs, and could finally be asked to develop their own historical questions, the choice of which could lead to the construction of a perspective from which the past can be seen and used as a stepping-stone for conducting students' eventual history research projects. This first level of narrative competence not only helps teachers to tap into what students think and feel about the topic at hand, but also stimulates student motivation for the following level, which takes more of a disciplinary-based approach.

At the next level of interpretation, students could be asked to probe their historical experiences by working on procedural concepts of historical thinking (Seixas \& Morton, 2013). Over the past years, Canadian researchers working on the Historical Thinking Project have developed a specific model of historical thinking that comprises six such second-order concepts (Seixas, 2015; Seixas \& Morton, 2013). To illustrate, Seixas (2015) outlines the concept of historical significance, which seeks to help students understand that something becomes historically significant, or worth knowing, only in relation to contemporary questions and concerns that depend on one's particular perspective and that necessarily change over time. There is also the concept of evidence or the use of primary sources, which is meant to enable students to contextualize the content and context of primary sources, that is, the people and circumstances of the past they refer to, as well as the present-day questions and scenarios that guide the inquiry and analysis of those sources. Another concept is that of causation (from cause and consequence), central to narrative competence, which promotes students' abilities to view change over time as shaped by a complex interplay of human freedom and agency, and to contextualize human decision-making in a way that communicates choice and intention, while accounting for larger social structures and conditions. Guiding students to work on these three concepts could help learners conduct original historical research using source-based evidence. For example, students might be introduced to the Narrative Template Tool's thread, Diversification through immigration, and asked to examine a given set of primary and secondary sources with the help of guided inquiry activities. Having assessed these sources for their reliability and validity, students would next be given the means to employ them as evidence to explore historical perspectives or to build historical explanations, thus furnishing the Diversification through immigration thread with their own narratives. At the end, students would write up a research report summarizing their main findings. 
The goal of instruction at the third level of narrative competence is that students transform their research reports into histories for reflection and guidance, thus giving an orienting function to the historical knowledge they construct. One way of doing this is simply by asking them to associate the elements of their research to the five elements of Kenneth Burke's (1969) Dramatistic Pentad: 1) Act, i.e., what happened; 2) Scene, i.e., where it happened, including circumstances, location, and time; 3) Agent, i.e., who is involved; 4) Agency, i.e., how it happened; 5) Purpose, i.e., why it happened. Teachers could have students combine their five elements in a narrative as part of creative writing tasks, using either one of the tool's two narrative themes and its chronological order for helping frame their resulting histories. By determining their guiding threads and which of the five periods of English-speaking Quebec's history they mostly focused on, students, together as a group activity, and with the teacher's guidance, could compare and contrast each other's narratives. Important to this discussion would be raising students' awareness of their authorship and positionality as well as comprehension of what their developed understandings of their community's past imply for civic action in the present.

\section{Conclusion: Promoting Autonomy and Open-Mindedness}

The central purpose of the Narrative Template Tool presented in this article is to function as a springboard for students to develop their own narratives of belonging to Quebec through investigative historical research. Through employing the tool, the point is to enhance English-speaking students' sense of group presence, coherency, and contributions. The intended outcome is to give them a sense of self-confidence and motivation for engaging in Quebec society as an empowered historic minority. Yet, despite its remedial intention, the tool's underlying script also runs the risk of being misused, especially if it is not employed flexibly. Given the nature of narrative and its political uses and abuses, there will always be a danger of promoting simplified stories to negative ends. Reducing the realities of past complexities, while necessary for grasping English-speakers' lived experiences, can also inadvertently lead to differentiating, distancing, and stereotyping Francophones and other minority groups in the province.

Bailey (2010) reminds us how "indoctrination [can] foster a certain style of belief that makes autonomy and open-mindedness unattainable" (p. 277). To counter indoctrination, the key is to foster a sense of autonomy among students to lead them "to make and act on well-informed and well-thought out judgments about how to live their own lives" and open-mindedness, or "a willingness to challenge or revise one's beliefs in certain circumstances" (p. 270). In order to implement the Narrative Template Tool without reinforcing group boundaries, a mechanism is called for to explicitly avoid closed-mindedness and indoctrination. The point is to help students freely develop their narratives of belonging without any interference from individuals in positions of authority, nor from the overpowering influence of pre-given narrative structures in the community that also risk producing such an outcome.

As an extension of the third sub-competency of orientation, the key here is to activate students' curiosity and to teach them about the practical, political, and cultural workings of narratives. This requires an open use of the narrative tool's core narrative script (i.e., the two themes and chronological structure) to ensure that students are able to develop well-informed and reasoned arguments for supporting their 
narratives of belonging, and to moreover be able to take critical distance from their resulting perspectives. This process also allows for the freedom to historicize and criticize the tool itself. Exercising students' understanding of orientation's key feature of "use-of-history" represents one such open-ended way of concretely employing the narrative tool. Through it, students would learn to see the benefits and drawbacks of developing community narratives (Nordgren, 2016). As a result, they would become informed and able to accept, reject, or adapt the general historical visions that narrate their community and its relations with other groups. They would also be able to position themselves and see where they stand vis-à-vis the production of their own stories of belonging.

In following "use-of-history" as a method of analysis, students would thus be able to (Nordgren, 2016; Nordgren \& Johansson, 2015): 1) Explain the surrounding world, where they learn to explain how differing groups use history to describe the world and give meaning to social reality. 2) Form identities, where they understand how these same differing cultures employ history for building and reshaping group identities. 3) Exert influence, or inform the surrounding world, which involves understanding how societies employ history to affect various (socio-political) situations, to act upon the world around them, and to promote social change.

In following this logic, "use-of-history" ultimately offers an opportunity for viewing history as basic to life orientation, where students see that they are an important part of history and that they consequently are their own authors of progress and change (Nordgren, 2016; Nordgren \& Johansson, 2015). Through grasping "use-of-history's" core workings, such an approach would serve to reinforce students' critical gaze and self-reflection and would foster their potential of being accountable for their differing positionalities. This would offer opportunities to assess the soundness of their produced histories at a larger, societal level of belonging. They would come to question what their narratives and underlying viewpoints expose and obscure about the world they live in and where they stand in light of it all (Freedman, 2007). Ultimately, they would be able to weigh the pros and cons of what they are actually saying, and also negating, in terms of the perspectives and ideas they put forth.

\section{Acknowledgments}

The template-like narrative tool presented in this article is based on the findings of a study funded by the Social Sciences and Humanities Research Council of Canada (SSHRC), which was awarded to Dr. Paul Zanazanian in 2013 for his research project entitled: Historical Consciousness and Community Education: How English-Speaking Community Leaders in Quebec Make Sense of the Past for Fostering Community Vitality and Civic Engagement. 


\section{References}

Ahonen, S. (2005). Historical consciousness: A viable paradigm for history education? Journal of Curriculum Studies, 37(6), 697-707.

Angvik, M., \& von Borries, B. (Eds.). (1997). Youth and history: A comparative European survey on historical consciousness and political attitudes among adolescents. Hamburg: Korber-Stiftung.

Assmann, J., \& Czaplicka, J. (1995). Collective memory and cultural identity. New German Critique, 65, Cultural history/ Cultural studies (Spring-Summer), 125-133.

Bailey, R. (2010). Indoctrination. In R. Bailey, R. Barrow, D. Carr, \& C. McCarthy (Eds.), The SAGE handbook of philosophy of education (pp. 269-282). London: SAGE Publications.

Barton, K. C. (2012). School history as a resource for constructing identities: Implications of research from the United States, Northern Ireland, and New Zealand. In M. Carretero, M. Asensio, \& M. R. Moneo (Eds.), History education and the construction of national identities (pp. 93-108). Charlotte, NC: Information Age Publishers.

Barton, K. C., \& Levstik, L. S. (2004). Teaching history for the common good. Mahwah, NJ: Lawrence Erlbaum Associates.

Bruner, J. S. (1990). Acts of meaning. Cambridge: Harvard University Press.

Burke, K. (1969). A grammar of motives. Berkeley: University of California Press.

Canadian Heritage. (2011). A portrait of the English-speaking communities in Quebec (Ottawa: Official Languages Support Programs Branch, Canadian Heritage).

Carretero, M., Asensio, M., \& Moneo, M. R. (Eds.). (2012). History education and the construction of national identities. Charlotte, NC: Information Age Publishers.

Carretero, M., Berger, S., \& Grever, M. (Eds.). (2017). Palgrave handbook of research in historical culture and education. London: Palgrave Macmillan.

Clark, P. (Ed.) (2011). New possibilities for the past: Shaping history education in Canada. Vancouver: UBC Press.

Colby, S. (2008). Energizing the history classroom: Historical narrative inquiry and historical empathy. Social Studies Research and Practice, 3(3), 60-79.

Eliasson, P., Alven, F., Yngveus, C. A., \& Rosenlund, D. (2015). Historical consciousness and historical thinking reflected in large-scale assessment in Sweden. In K. Ercikan \& P. Seixas (Eds.), New direction in assessing historical thinking (pp. 171-182). New York, NY: Routledge.

Epstein, T. (2008). Interpreting national history: Race, identity, and pedagogy in classrooms and communities. New York, NY: Routledge.

Epstein, T., \& Peck, C. L. (Eds.). (2017). Teaching and learning difficult histories in international contexts: A critical sociocultural approach. New York, NY: Routledge.

Freedman, E. B. (2007). Is teaching for social justice undemocratic? Harvard Educational Review, 77(4), $442-473$. 
Using a Narrative Tool to Help Quebec English-Speaking Students Produce Personal Histories of Belonging

Halbwachs, M. (1992). On collective memory. (L. A. Coser, Trans.). Chicago, IL: University of Chicago Press. (Original works published in 1941 \& 1952).

Körber, A., \& Meyer-Hamme, J. (2015). Historical thinking, competencies, and their measurement. In K. Ercikan \& P. Seixas (Eds.), New direction in assessing historical thinking (pp. 89-101). New York, NY: Routledge.

Köster, M., Thünemann, H., \& Zülsdorf-Kersting, M. (Eds.). (2014). Researching history education: International perspectives and disciplinary traditions. Schwalbach: Wochenschau.

Lee, P. (2004). 'Walking backwards into tomorrow'. Historical consciousness and understanding history. International Journal of Historical Learning, Teaching and Research, 4(1), 69-114.

Létourneau, J. (2006). Mythistoires de 'Losers': Introduction au roman historial des Québécois d'héritage canadien-français. Histoire sociale/Social History, 39(77), 157-180.

Létourneau, J. (2014). Je me souviens? Le passé du Québec dans la conscience de sa jeunesse. Montreal: Fides.

Létourneau, J. (2015). Pour une pragmatique de l'enseignement de l'histoire. Leçons tirées d'une recherche. Special issue: Dossier 1, Récits et mises en texte du passé, À l'école de Clio. Retrieved from http://ecoleclio.hypotheses.org/212.

Létourneau, J., \& Moisan, M. (2004). Young people's assimilation of a collective historical memory: A case study of Quebeckers of French-Canadian heritage. In P. Seixas (Ed.), Theorizing historical consciousness (pp. 109-128). Toronto: Toronto University Press.

Nordgren, K. (2016). How to do things with history: Use of history as a link between historical consciousness and historical culture. Theory \& Research in Social Education, 44(4), 479-504.

Nordgren, K., \& Johansson, M. (2015). Intercultural historical learning: A conceptual framework. Journal of Curriculum Studies, 47(1), 1-25.

Phillips, D. (Ed.). (2000). Constructivism in education. Chicago, IL: University of Chicago Press.

Polkinghorne, D. (1988). Narrative knowing and the human sciences. Albany, NY: State University of New York Press.

Quebec Community Groups Network. (2009). Creating spaces for young Quebecers: Strategic orientations for English-speaking Youth in Quebec. Montreal: Quebec Community Groups Network's Youth Standing Committee and Canadian Heritage.

Renshaw P.D. (2004). Dialogic learning teaching and instruction. In J. van der Linden \& P. Renshaw (Eds.), Dialogic learning (pp. 1-15). Dordrecht: Springer.

Rüsen, J. (2005). History: Narration, interpretation, orientation. New York, NY: Berghahn Books.

Seixas, P. (Ed.). (2004). Theorizing historical consciousness. Toronto: University of Toronto Press.

Seixas, P. (2015). A model of historical thinking. Educational Philosophy and Theory, 1-13. doi:10.1080/00131857.2015.1101363

Seixas, P., \& Morton, T. (2013). The big six historical thinking concepts. Toronto: Nelson Education. 
Senate Committee on Official Languages. (2011). The vitality of Quebec's English-speaking communities: From myth to reality (Ottawa, Senate of Canada: Report of the Standing Senate Committee on Official Languages).

Stearns, P. N., Seixas, P., \& Wineburg, S. (Eds.). (2000). Knowing, teaching and learning history: National and international perspectives. New York, NY: New York University Press.

Straub, J. (2005). Telling stories, making history: Toward a narrative psychology of the historical construction of meaning. In J. Straub (Ed.), Narrative identity, and historical consciousness (pp. 44-98). New York, NY: Berghahn Books.

van Boxtel, C., Grever, M., \& Klein, S. (Eds.). (2016). Sensitive pasts: Questioning heritage in education. New York, NY: Berghahn Books.

VanSledright, B. A. (1998). On the importance of historical positionality to thinking about and teaching history. International Journal of Social Education, 12(2), 1-18.

Waldis, M., Hodel, J., Thünemann, H., Zülsdorf-Kersting, M., \& Ziegler, B. (2015). Material-based and open-ended writing tasks for assessing narrative competence among students. In K. Ercikan \& P. Seixas (Eds.), New directions in assessing historical thinking (pp. 117-131). New York, NY: Routledge.

Wertsch, J. (1998). Mind as action. New York, NY: Oxford University Press.

Wertsch, J. (2004). Specific narratives and schematic narrative templates. In P. Seixas (Ed.), Theorizing historical consciousness (pp. 49-62). Toronto: University of Toronto Press.

Wilschut, A. (2012). Images of time: The role of a historical consciousness of time in learning history. Charlotte, NC: Information Age Publishing.

Wineburg, S. (2001). Historical thinking and other unnatural acts: Charting the future of teaching the past. Philadelphia, PA: Temple University Press.

Zanazanian, P. (2017a). Vers un schéma narratif pour donner une place à la minorité anglophone dans I'enseignement de I'histoire au Québec. Didactica Historica, 3, 1-13.

Zanazanian, P. (2017b). Teaching history for narrative space and vitality: Historical consciousness, templates, and English-speaking Quebec. In H. Å. Elmersjö, A. Clark, \& M. Vinterek (Eds.), Teaching rival histories: Pedagogical responses to the history culture wars (pp. 107-131). London: Palgrave Macmillan.

Zanazanian, P., \& Moisan, S. (2012). Harmonizing two of history teaching's main social functions: Franco-Québécois history teachers and their predispositions to catering to narrative diversity. Education Sciences, Special issue: History Curriculum, Geschichtsdidaktik, and the Problem of the Nation, 2(4), 255-275. 


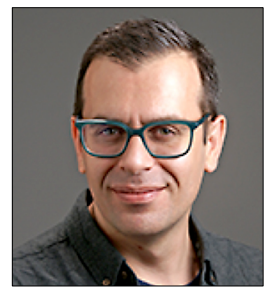

Paul Zanazanian is an Associate Professor in the Department of Integrated Studies in Education at McGill University. His research explores the workings of historical consciousness in the development of individual and We-subject identities, with a particular focus on formal and informal school settings. His work examines practitioners' historical sense-making and its impacts on their awareness of self and agency, informing their social posture in their roles as teachers and community educators. His interests include the politics of history teaching; official state narratives and issues of exclusion; and problems of history, identity, and community vitality in complex societies (i.e., English-speaking Quebec).

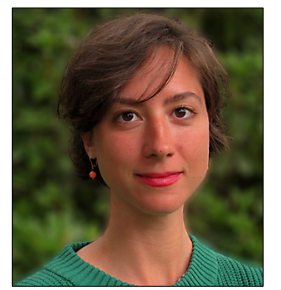

Nathalie Popa is a PhD Candidate in Educational Studies at McGill University. She holds a B.A. in History from the Université de Montréal, and an M.A. in History from McGill University. Her research interests include social studies education, instructional design, and motivation to learn. Her doctoral research project explores how the concept of historical consciousness can be applied to educational practice in high school history lessons, and her research is supported by the Fonds de recherche du Québec - Société et culture. 